\title{
Regioselective Synthesis of Some Pyrazole Scaffolds Attached to Benzothiazole and Benzimidazole Moieties
}

\author{
Nabila A. Kheder, ${ }^{1,2}$ Yahia N. Mabkhot, ${ }^{3}$ Fawzia R. Zahian, ${ }^{2}$ and Sara S. Mohamed ${ }^{2}$ \\ ${ }^{1}$ Department of Chemistry, Faculty of Science, Cairo University, Giza 12613, Egypt \\ ${ }^{2}$ Department of Pharmaceutical Chemistry, Faculty of Pharmacy, King Khalid University, Abha 61441, Saudi Arabia \\ ${ }^{3}$ Department of Chemistry, College of Science, King Saud University, P.O. Box 2455, Riyadh 11451, Saudi Arabia
}

Correspondence should be addressed to Nabila A. Kheder; nabila_abdelshafy@yahoo.com and Yahia N. Mabkhot; yahia@ksu.edu.sa

Received 7 January 2014; Accepted 5 February 2014; Published 10 March 2014

Academic Editor: Nihal Onul

Copyright (c) 2014 Nabila A. Kheder et al. This is an open access article distributed under the Creative Commons Attribution License, which permits unrestricted use, distribution, and reproduction in any medium, provided the original work is properly cited.

Condensation of 2-(benzothiazol-2-yl)acetonitrile (1) or 2-(1-methyl-1H-benzimidazol-2-yl)acetonitrile (2) with thiophene-2carbaldehyde afforded the corresponding acrylonitrile derivatives $\mathbf{3}$ or $\mathbf{4}$, respectively. The 1,3-dipolar cycloaddition reaction of the acrylonitrile 3 or $\mathbf{4}$ with nitrile-imine $\mathbf{6}$ gave novel pyrazole derivatives pendant to benzothiazole and benzimidazole. The pyrazoline derivative $\mathbf{7}$ was converted into the corresponding pyrazole derivative $\mathbf{1 1}$ via thermal elimination of hydrogen cyanide upon heating in sodium ethoxide solution. The structures of the synthesized products were confirmed by IR, ${ }^{1} \mathrm{H}$ NMR, and mass spectral techniques.

\section{Introduction}

Benzothiazole derivatives have been reported to possess diverse biological properties $[1,2]$. Benzimidazole is an interesting heterocyclic ring system because it is present in naturally occurring cyanocobalamin and several known commercialized drugs such as mebendazole, astemizole, and emedastine difumarate. Moreover, they have shown anthelmintic [3] and antimicrobial activities [4-6]. Also, many benzimidazole derivatives are used as inhibitors of HIV-1 that causes AIDS [7-9] as well as anticancer agents [10]. In addition, pyrazoline derivatives have been found antifungal [11], antidepressant [12-15], anticonvulsant [14, 15], anti-inflammatory [16], antibacterial [17], and antitumor [18] properties. Also, thiophene derivatives are important heterocycles found in several biologically active and natural compounds [19-21]. For example, 2-amino-3-aroylthiophene derivatives are reported as agonist allosteric enhancers at the $\mathrm{A} 1$ adenosine receptor $[22,23]$. In view of the abovementioned findings and in continuation of our previous work aimed at the synthesis of a variety of heterocyclic ring systems for biological and pharmacological evaluation [2429], we report here an efficient method for the synthesis of some pyrazole derivatives attached to benzothiazole and benzimidazole moieties.

\section{Experimental Section}

2.1. Materials and Methods. All melting points were measured on a Gallenkamp melting point apparatus (WeissGallenkamp, London, UK). The infrared spectra were recorded in potassium bromide disks on a Pye Unicam SP 3300 and Shimadzu FT-IR 8101 PC infrared spectrophotometers (Pye Unicam Ltd. Cambridge, England, and Shimadzu, Tokyo, Japan, resp.). The NMR spectra were recorded on a Varian Mercury VX-300 NMR spectrometer (Varian, Palo Alto, CA, USA). ${ }^{1} \mathrm{H}$ spectra were run at $300 \mathrm{MHz}$ in deuterated chloroform $\left(\mathrm{CDCl}_{3}\right)$ or dimethyl sulphoxide (DMSO$d_{6}$ ). Chemical shifts were related to that of the solvent. Mass spectra were recorded on a Shimadzu GCMS-QP 1000 EX mass spectrometer (Shimadzu) at $70 \mathrm{eV}$. The starting materials 2-(benzothiazol-2-yl)acetonitrile (1) [30], 2-(1methyl-1H-benzimidazol-2-yl)acetonitrile (2) [31,32], and $N^{\prime}$-phenylbenzohydrazonoyl chloride 5 [33] were prepared according to the reported literature procedures. 


\subsection{Synthesis}

\subsubsection{Synthesis of 2-(Benzothiazol-2-yl)-3-(thiophen-2-yl)acry-} lonitrile (3) and 2-(1-Methyl-1H-benzimidazol-2-yl)-3(thiophen-2-yl)acrylonitrile (4)

General Procedure. To a mixture of acetonitrile $\mathbf{1}$ or $\mathbf{2}$ (10 mmol) and the thiophene 2-carbaldehyde $(10 \mathrm{mmol})$ in ethanol $(10 \mathrm{~mL})$, piperidine $(0.2 \mathrm{~mL})$ was added, and the mixture was refluxed for $30 \mathrm{~min}$. The formed coloured crystalline products were collected by filtration, washed with ethanol, and dried. Recrystallization from the appropriate solvent gave 3 or $\mathbf{4}$, respectively.

(1) 2-(Benzothiazol-2-yl)-3-(thiophen-2-yl)acrylonitrile (3). Yield (70\%), mp 156-7 $7^{\circ}$; IR (KBr) v $2211(\mathrm{C} \equiv \mathrm{N}), 3055$ (aromatic CH) cm ${ }^{-1} ;{ }^{1} \mathrm{H}$ NMR [DMSO-d 6 ] $\delta$ 7.34-7.60 $(\mathrm{m}, 3 \mathrm{H}), 8.04-8.18(\mathrm{~m}, 4 \mathrm{H}), 8.68(\mathrm{~s}, 1 \mathrm{H}) ; \mathrm{MS} \mathrm{m} / \mathrm{z}(\%) 268$ $\left(\mathrm{M}^{+}, 100.0\right), 242$ (7.81), 134 (9.6), 83 (1.14). Anal. Calcd for $\mathrm{C}_{14} \mathrm{H}_{8} \mathrm{~N}_{2} \mathrm{~S}_{2}$ : C, 62.66; H, 3.00; N, 10.44. Found: C, 62.75; H, $3.12 ; \mathrm{N}, 10.35 \%$.

(2) 2-(1-Methyl-1H-benzimidazol-2-yl)-3-(thiophen-2-yl)acrylonitrile (4). Yield (75\%), mp. $100^{\circ} \mathrm{C}$ (methanol); IR (KBr) v $1609(\mathrm{C}=\mathrm{N}), 2207(\mathrm{C} \equiv \mathrm{N}), 2956$ (aliphatic $\mathrm{CH}), 3087$ (aromatic CH) cm ${ }^{-1} ;{ }^{1} \mathrm{H}$ NMR [DMSO-d 6 ] $4.0(\mathrm{~s}, 3 \mathrm{H}$, $\left.\mathrm{CH}_{3}\right), 7.25-7.36(\mathrm{~m}, 3 \mathrm{H}), 7.63-7.70(\mathrm{~m}, 2 \mathrm{H}), 7.95(\mathrm{~d}, 1 \mathrm{H}), 8.08$ (d, 1H), 8.47 (s, 1H); MS m/z (\%) 267 (5.96), $265\left(\mathrm{M}^{+}, 100.0\right)$, 131 (23.95), 83 (4.47). Anal. Calcd for $\mathrm{C}_{15} \mathrm{H}_{11} \mathrm{~N}_{3} \mathrm{~S}$ : C, 67.90; $\mathrm{H}$, 4.18; N, 15.84. Found: C, 67.82; H, 4.25; N, 15.77\%.

\subsubsection{Synthesis of 5-Cyanopyrazole Derivatives 7 and 9}

General Procedure. Equimolar quantities of the appropriate acrylonitrile 3 or $4(5 \mathrm{mmol})$ and $N^{\prime}$-phenylbenzohydrazonoyl chloride 5 ( $5 \mathrm{mmol})$ were dissolved in dry benzene $(20 \mathrm{~mL})$. To the resulting solution, triethylamine $(0.5 \mathrm{~mL}$, $5 \mathrm{mmol}$ ) was added and the reaction mixture was stirred for $12 \mathrm{~h}$, and then the solvent was distilled under reduced pressure. The oil residue was triturated with $\mathrm{MeOH}$ and the solid product was collected by filtration, washed with methanol, and recrystallized from the suitable solvent to afford the corresponding pyrazole derivatives 7 and $\mathbf{9}$, respectively.

(1) 5-(Benzothiazol-2-yl)-1,3-diphenyl-4-(thiophen-2-yl)-4,5dihydro-1H-pyrazole-5-carbonitrile (7). Yield (56\%), mp. $190-1^{\circ} \mathrm{C}$; IR $(\mathrm{KBr})$ v $1600(\mathrm{C}=\mathrm{N}) \mathrm{cm}^{-1} ;{ }^{1} \mathrm{H} \mathrm{NMR}\left[\mathrm{CDCl}_{3}\right]$ $\delta 5.68(\mathrm{~s}, 1 \mathrm{H}$, Pyrazole-H), 7.02-8.19 (m, 17H, ArH); MS $\mathrm{m} / \mathrm{z}$ (\%) 465 (2.1), 464 (8.1), $463\left(\mathrm{M}^{+}, 14.4\right)$. Anal. Calcd for $\mathrm{C}_{27} \mathrm{H}_{18} \mathrm{~N}_{4} \mathrm{~S}_{2}$ : C, 70.10; H, 3.92; N, 12.11. Found: C, 70.05; H, $3.85 ; \mathrm{N}, 12.17 \%$.

(2) 5-(1-Methyl-1H-benzimidazol-2-yl)-1,3-diphenyl-4-(thiophen-2-yl)-4,5-dihydro-1H-pyrazole-5-carbonitrile (9). Yield (45\%), mp. 176-7 ${ }^{\circ} \mathrm{C}$ (ethanol); IR (KBr) v $1600(\mathrm{C}=\mathrm{N}) \mathrm{cm}^{-1}$;
${ }^{1} \mathrm{H}$ NMR $\left[\mathrm{CDCl}_{3}\right] \delta 3.71\left(\mathrm{~s}, 3 \mathrm{H}, \mathrm{CH}_{3}\right), 5.66$ (s, $1 \mathrm{H}$, Pyrazole$\mathrm{H})$, 6.95-7.96 (m, 17H, ArH). For $\mathrm{C}_{28} \mathrm{H}_{21} \mathrm{~N}_{5} \mathrm{~S}$ Calcd.: C, 73.18; H, 4.61; N, 15.24. Found: C, 73.09; H, 4.66; N, 15.18\%.

(3) Synthesis of 2-(1,3-diphenyl-4-(thiophen-2-yl)-1H-pyrazol5-yl)benzothiazole (11). A mixture of 5-cyanopyrazole 7 $(1.38 \mathrm{~g}, 3 \mathrm{mmol})$ and sodium ethoxide (prepared from sodium metal $(0.07 \mathrm{~g}, 3 \mathrm{mmol})$ in EtOH $(15 \mathrm{~mL})$ ) was heated under reflux for $1 \mathrm{~h}$ and then left to cool. The precipitated solid was collected by filtration, washed with water, and recrystallized from ethanol to give compound 11 in $75 \%$ yield, mp. $178-9^{\circ} \mathrm{C}$ (ethanol); IR (KBr) $v 1600(\mathrm{C}=\mathrm{N}) \mathrm{cm}^{-1} ;{ }^{1} \mathrm{H}$ NMR $\left[\mathrm{CDCl}_{3}\right] \delta$ 7.04-7.99 (m, ArH); MS m/z (\%) 438 (1.6), 437 (8.1), $436\left(\mathrm{M}^{+}\right.$, 25.4), 352 (1.3), 134 (2.8), 83 (1.6), 77 (100.0). For $\mathrm{C}_{26} \mathrm{H}_{17} \mathrm{~N}_{3} \mathrm{~S}_{2}$ Calcd.: C, 71.70; H, 3.93; N, 9.65. Found: C, 71.79; H, 3.98; N, $9.60 \%$.

\section{Results and Discussion}

The key starting materials 2-(benzothiazol-2-yl)acetonitrile (1) [30] and 2-(1-methyl-1H-benzimidazol-2-yl)acetonitrile (2) $[31,32]$ are characterized by the presence of an active methylene as well as nitrile function which makes them active so they can be used as a precursors for the synthesis of biologically and chemically active compounds. In the present work, the synthetic potential of the acrylonitriles $\mathbf{3}$ and $\mathbf{4}$ has been explored.

The usual method for the synthesis of acrylonitrile 3 or 4 employs condensation of 2-(benzothiazol-2-yl)acetonitrile (1) or 2-(1-methyl-1H-benzimidazol-2-yl)acetonitrile (2) with thiophene-2-carbaldehyde in refluxing ethanol containing a catalytic amount of piperidine (Scheme 1). The analytical and spectroscopic data were consistent with the final products 3 and 4 (see Section 2).

Treatment of compound 3 with nitrile imine 6 (generated in situ from $N^{\prime}$-phenylbenzohydrazonoyl chloride $\mathbf{5}$ [33] by the action of triethylamine in benzene) afforded only one cycloadduct as deduced from TLC and ${ }^{1} \mathrm{H}$ NMR analysis of the crude reaction product (Scheme 2). The structure of the isolated cycloadduct was assigned as 5-(benzothiazol-2-yl)-1,3-diphenyl-4-(thiophen-2-yl)-4,5dihydro- $1 H$-pyrazole-5-carbonitrile (7) based on its elemental analysis and its spectroscopic data. The distinction between the two possible regioisomeric cycloadducts 7 and 8 (Figure 1) was made on the basis of the IR and ${ }^{1} \mathrm{H}$ NMR spectra of the isolated product.

The structure of the product 7 was in agreement with its elemental analysis and spectroscopic data. Although compound 7 bears a nitrile function, its IR spectrum did not afford nitrile absorption band similar to the case of aliphatic nitriles activated by a nitrogen or oxygen atom in the $\alpha$ position $[34,35]$. This similarity of the absence of the nitrile absorption in the IR spectrum excludes the possibility of the other regioisomer $\mathbf{8}$ for the isolated product. This is because compound of type $\mathbf{8}$ is expected to exhibit strong nitrile absorption in their IR spectra [36]. 


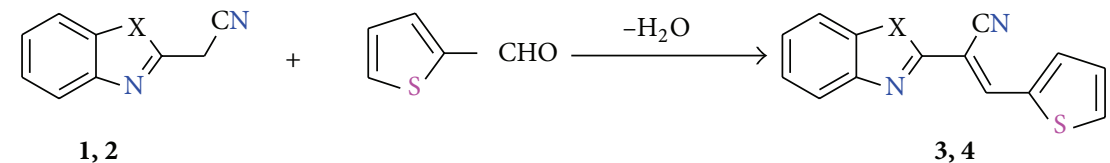

1,3: $\mathrm{X}=\mathrm{S}$

2, 4: $\mathrm{X}=\mathrm{NMe}$

SCHEME 1

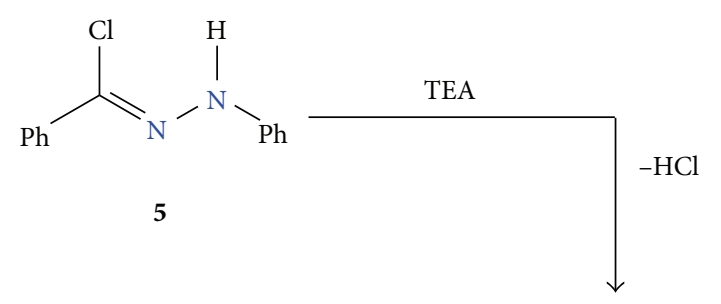<smiles>N#C/C(=C\c1cccs1)c1[X]c2ccccc2n1</smiles>

3,4

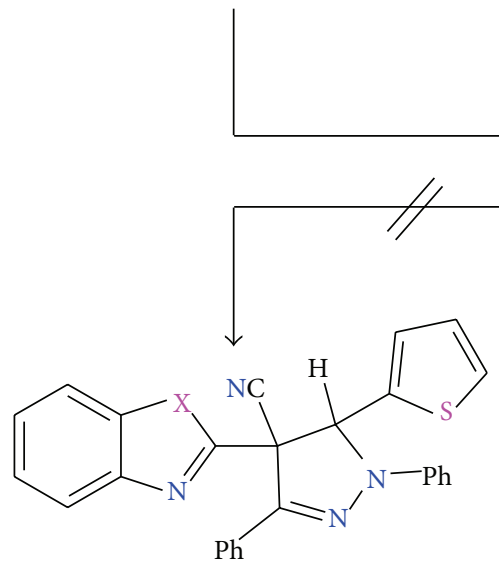

8,10<smiles>[C+](=N[P-]N=[PH]c1ccccc1)c1ccccc1</smiles>
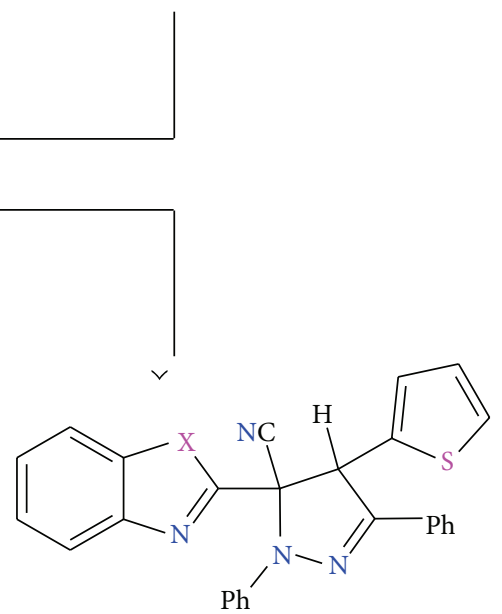

7,9

3, 7, 8: $X=S$

4, 9, 10: $\mathrm{X}=\mathrm{NMe}$

Scheme 2

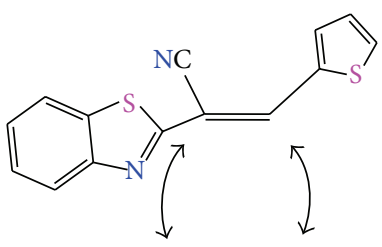

$\oplus \quad \Theta$

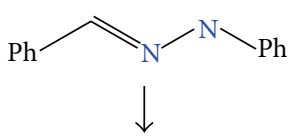

8

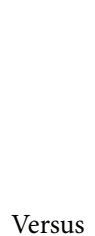

Versus
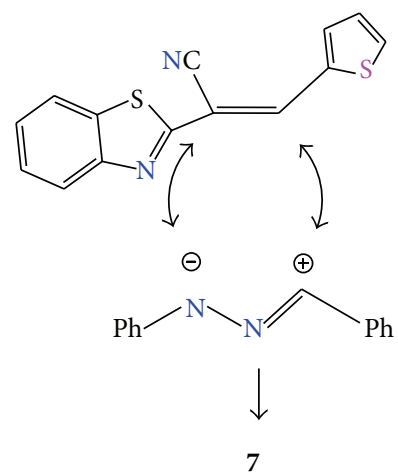

Figure 1: The two possible regioisomeric cycloadducts 7 and $\mathbf{8 .}$ 


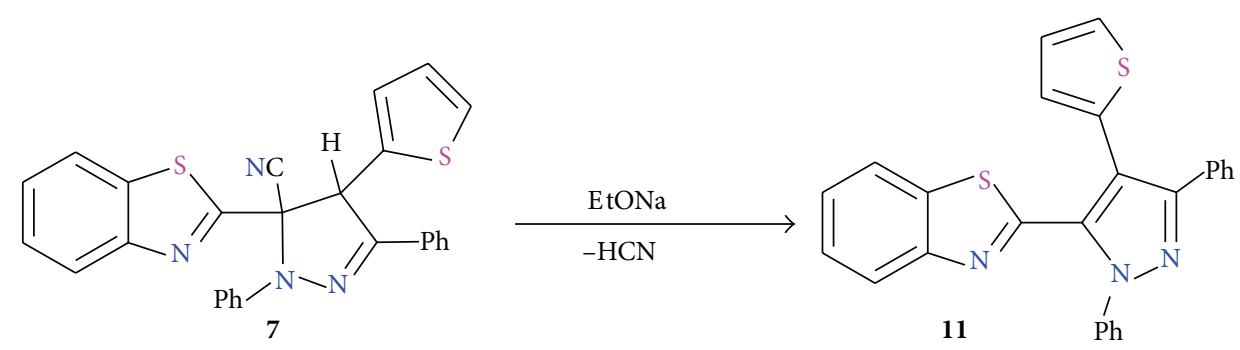

SCHEMe 3

In analogous manner, the nitrile imine $\mathbf{6}$ added regioselectively to the carbon-carbon double bond of 2-(1-methyl$1 H$-benzimidazol-2-yl)-3-(thiophen-2-yl)acrylonitrile (4) in benzene at room temperature to afford 5-(1-methyl- $1 \mathrm{H}$ benzoimidazol-2-yl)-1,3-diphenyl-4-(thiophen-2-yl)-4,5-dihydro- $1 \mathrm{H}$-pyrazole-5-carbonitrile (9) (Scheme 2). The structure of the latter product was assigned on the basis of its elemental analysis and spectral data. For example, its IR spectrum revealed no nitrile absorption band. Moreover, structure 9 was confirmed by ${ }^{1} \mathrm{H}$ NMR spectrum which revealed a sharp singlet signal at $\delta 5.66$ assignable to the proton at C-4 of the pyrazoline ring. This chemical shift is very similar to those reported for the C-4 proton of 4,5-dihydro- $1 H$-pyrazole derivatives [37].

When compound 7 was heated in ethanolic sodium ethoxide solution, it afforded the pyrazole derivative $\mathbf{1 1}$ in high yield (Scheme 3 ). The structure of the product was confirmed by ${ }^{1} \mathrm{H}$ NMR spectra, which revealed the disappearance of the proton signal at C-4.

\section{Conclusion}

We have successfully synthesized some pyrazole derivatives attached to benzothiazole and benzimidazole moieties of biological and pharmacological interest, via 1,3-dipolar cycloaddition reaction.

\section{Conflict of Interests}

The authors declare that there is no conflict of interests.

\section{Acknowledgment}

The authors extend their appreciation to the Deanship of Scientific Research at King Saud University for funding the work through the Research Group Project no. RGP-VPP-007.

\section{References}

[1] A. Rana, N. Siddiqui, and S. A. Khan, "Benzothiazoles: a new profile of biological activities," Indian Journal of Pharmaceutical Sciences, vol. 69, no. 1, pp. 10-17, 2007.

[2] G. Wells, T. D. Bradshaw, P. Diana et al., "Antitumour benzothiazoles-part 10: the synthesis and antitumour activity of benzothiazole substituted quinol derivatives," Bioorganic and Medicinal Chemistry Letters, vol. 10, no. 5, pp. 513-515, 2000.
[3] Q. A. McKellar and E. W. Scott, "The benzimidazole anthelmintic agents-a review," Journal of Veterinary Pharmacology and Therapeutics, vol. 13, no. 3, pp. 223-247, 1990.

[4] H. Göker, M. Tunçbilek, S. Süzen, C. Kus, and N. Altanlar, "Synthesis and antimicrobial activity of some new 2phenyl-N-substituted carboxamido-1H-benzimidazole derivatives," Archiv der Pharmazie, vol. 334, no. 5, pp. 148-152, 2001.

[5] G. Ayhan-Kilcigil and N. Altanlar, "Synthesis and antimicrobial activities of some new benzimidazole derivatives," Farmaco, vol. 58, no. 12, pp. 1345-1350, 2003.

[6] Ö. Ö. Güven, T. Erdoǧan, H. Göker, and S. Yildiz, "Synthesis and antimicrobial activity of some novel phenyl and benzimidazole substituted benzyl ethers," Bioorganic and Medicinal Chemistry Letters, vol. 17, no. 8, pp. 2233-2236, 2007.

[7] A. Chimirri, S. Grasso, P. Monforte et al., "Synthesis and biological activity of novel $1 \mathrm{H}, 3 \mathrm{H}$-thiazolo[3,4-a]benzimidazoles: non-nucleoside human immunodeficiency virus type 1 reverse transcriptase inhibitors," Antiviral Chemistry and Chemotherapy, vol. 10, no. 4, pp. 211-217, 1999.

[8] T. M. Evans, J. M. Gardiner, N. Mahmood, and M. Smis, "Structure-activity relationships of anti-HIV-1 N-alkoxy- and N-allyloxy-benzimidazoles," Bioorganic and Medicinal Chemistry Letters, vol. 7, no. 4, pp. 409-412, 1997.

[9] T. Roth, M. L. Morningstar, P. L. Boyer, S. H. Hughes, R. W. Buckheit Jr., and C. J. Michejda, "Synthesis and biological activity of novel nonnucleoside inhibitors of HIV-1 reverse transcriptase. 2-Aryl-substituted benzimidazoles," Journal of Medicinal Chemistry, vol. 40, no. 26, pp. 4199-4207, 1997.

[10] K.-J. Soderlind, B. Gorodetsky, A. K. Singh, N. R. Bachur, G. G. Miller, and J. W. Lown, "Bis-benzimidazole anticancer agents: targeting human tumour helicases," Anti-Cancer Drug Design, vol. 14, no. 1, pp. 19-36, 1999.

[11] S. S. Korgaokar, P. H. Patil, M. J. Shah, and H. H. Parekh, "Studies on pyrazolines: preparation and antimicrobial activity of 3-3'(P-chlorophenylsulphonamidophenyl)-5 aryl-1H/acetyl pyrazolines," Indian Journal of Pharmaceutical Sciences, vol. 58, no. 6, pp. 222-225, 1996.

[12] E. Palaska, M. Aytemir, I. T. Uzbay, and D. Erol, "Synthesis and antidepressant activities of some 3,5-diphenyl-2-pyrazolines," European Journal of Medicinal Chemistry, vol. 36, no. 6, pp. 539543, 2001.

[13] Y. Rajendra Prasad, A. Lakshmana Rao, L. Prasoona, K. Murali, and P. Ravi Kumar, "Synthesis and antidepressant activity of some 1,3,5-triphenyl-2-pyrazolines and 3-(2"-hydroxy naphthalen-1" ${ }^{\prime \prime}$-yl)-1,5-diphenyl-2-pyrazolines," Bioorganic and Medicinal Chemistry Letters, vol. 15, no. 22, pp. 5030-5034, 2005.

[14] Z. Özdemir, H. B. Kandilci, B. Gümüşel, Ü. Çaliş, and A. A. Bilgin, "Synthesis and studies on antidepressant and anticonvulsant activities of some 3-(2-furyl)-pyrazoline derivatives," 
European Journal of Medicinal Chemistry, vol. 42, no. 3, pp. 373379, 2007.

[15] O. Ruhoǧlu, Z. Özdemir, Ü. Çaliş, B. Gümüşel, and A. A. Bilgin, "Synthesis of and pharmacological studies on the antidepressant and anticonvulsant activities of some 1,3,5-trisubstituted pyrazolines," Arzneimittel-Forschung/Drug Research, vol. 55, no. 8, pp. 431-436, 2005.

[16] R. H. Udupi, A. S. Kushnoor, and A. R. Bhat, "Synthesis and biological evaluation of certain pyrazoline derivatives of 2-[6methoxy naphthyl]-propionic acid (naproxen)," Indian Journal of Heterocyclic Chemistry, vol. 8, no. 1, pp. 63-66, 1998.

[17] S. Kini and A. Gandhi, "Novel 2-pyrazoline derivatives as potential antibacterial and antifungal agents," Indian Journal of Pharmaceutical Sciences, vol. 70, no. 1, pp. 105-108, 2008.

[18] P. J. Jainey and I. K. Bhat, "Antitumor, analgesic, and antiinflammatory activities of synthesized pyrazolines," Journal of Young Pharmacists, vol. 4, no. 2, pp. 82-87, 2012.

[19] C. Heyde, I. Zug, and H. Hartmann, "A simple route to N,N-dialkyl derivatives of 2-amino-5-thiophenecarboxylates," European Journal of Organic Chemistry, vol. 2000, no. 19, pp. 3273-3278, 2000.

[20] A. Noack and H. Hartmann, "Synthesis and characterisation of N,N-disubstituted 2-amino-5-acylthiophenes and 2-amino5-acylthiazoles," Tetrahedron, vol. 58, no. 11, pp. 2137-2146, 2002.

[21] T. S. Jagodziński, "Thioamides as useful synthons in the synthesis of heterocycles," Chemical Reviews, vol. 103, no. 1, pp. 197-227, 2003.

[22] C. E. Tranberg, A. Zickgraf, B. N. Giunta et al., "2-Amino3-aroyl-4,5-alkylthiophenes: agonist allosteric enhancers at human al adenosine receptors," Journal of Medicinal Chemistry, vol. 45, no. 2, pp. 382-389, 2002.

[23] A. P. Kourounakis, P. A. M. van der Klein, and A. P. Ijzerman, "Elucidation of structure-activity relationships of 2-amino3- benzoylthiophenes: study of their allosteric enhancing vs. antagonistic activity on adenosine A1 receptors," Drug Development Research, vol. 49, no. 4, pp. 227-237, 2000.

[24] N. A. Kheder, S. M. Riyadh, and A. M. Asiry, "Azoles and bisazoles: synthesis and biological evaluation as antimicrobial and anti-cancer agents," Chemical and Pharmaceutical Bulletin, vol. 61, no. 5, pp. 504-510, 2013.

[25] S. M. Riyadh, N. A. Kheder, and A. M. Asiry, "Synthesis, anticancer, and antimicrobial activities of some new antipyrinebased heterocycles," Chemical Monthly, vol. 144, no. 10, pp. 1559-1567, 2013.

[26] N. A. Kheder and Y. N. Mabkhot, "Synthesis and antimicrobial studies of some novel bis-[1,3,4]thiadiazole and bis-thiazole pendant to thieno[2,3-b]thiophene moiety," International Journal of Molecular Sciences, vol. 13, no. 3, pp. 3661-3670, 2012.

[27] Y. N. Mabkhot, N. A. Kheder, and A. M. Farag, "Synthesis and antimicrobial evaluation of some new tetrahydropyrimidine derivatives," Heterocycles, vol. 83, no. 3, pp. 609-617, 2011.

[28] N. A. Kheder, "Synthesis of some novel bis(pyrazole), bis(pyridine) and bis(pyrazolo[5,1-c]-1,2,4-triazine derivatives," Heterocycles, vol. 78, no. 7, pp. 1815-1822, 2009.

[29] N. A. Kheder, "Convenient synthesis of novel bis(hydrazone) and bis(indole) derivatives," Heterocycles, vol. 78, no. 5, pp. 12811288, 2009.

[30] K. Saito, S. Kambe, Y. Nakano, A. Sakurai, and H. Midorikawa, "Synthetic studies using $\alpha, \beta$-unsaturated nitriles: a convenient preparation of 1,3-benzothiazole derivatives," Synthesis, vol. 3, pp. $210-212,1983$.
[31] R. A. B. Copeland and A. R. Day, "The preparation and reactions of 2-benzimidazolecarboxylic acid and 2-benzimidazoleacetic acid," Journal of the American Chemical Society, vol. 65, no. 6, pp. 1072-1075, 1943.

[32] W. Ozegowski and D. Krebs, "Amino acid antagonists. IV Experiments for the preparation of [I-methyl-5-bis-(p-chlorathyl) aminobenzimidazolyl-(2)]-acetic acid," Journal für Praktische Chemie/Chemiker-Zeitung, vol. 29, p. 18, 1965.

[33] P. Wolkoff, "A new method of preparing hydrazonyl halides," Canadian Journal of Chemistry, vol. 53, no. 9, pp. 1333-1335, 1975.

[34] G. Butt, J. Cilmi, P. M. Hoobin, and R. D. Topsom, "The transmission of resonance effects through a methylene groupspectroscopic studies on some $\alpha$-substituted-acetonitriles and p-toluonitriles," Spectrochimica Acta A, vol. 36, no. 6, pp. 521524, 1980.

[35] J. P. Jesson and H. W. Thompson, "Vibrational band intensities of the $\mathrm{C} \equiv \mathrm{N}$ group in aliphatic nitriles," Spectrochimica Acta, vol. 13, no. 3, pp. 217-222, 1958.

[36] B. H. Thomas and W. J. Orville-Thomas, "Infrared intensities of $\mathrm{V}(\mathrm{C} \equiv \mathrm{N})$ bands," Journal of Molecular Structure, vol. 7, no. 1-2, pp. 123-135, 1971.

[37] A. K. Mansour, M. M. Eid, and N. S. A. M. Khalil, "Synthesis and reactions of some new heterocyclic carbohydrazides and related compounds as potential anticancer agents," Molecules, vol. 8, no. 10, pp. 744-755, 2003. 

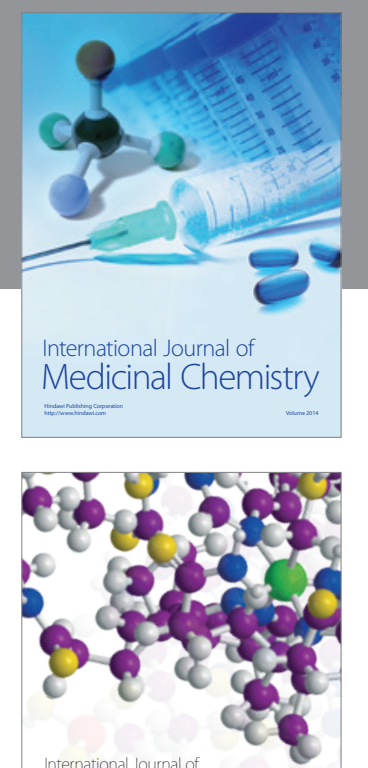

\section{Carbohydrate} Chemistry

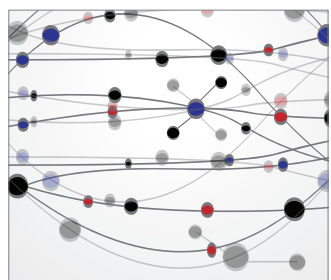

The Scientific World Journal
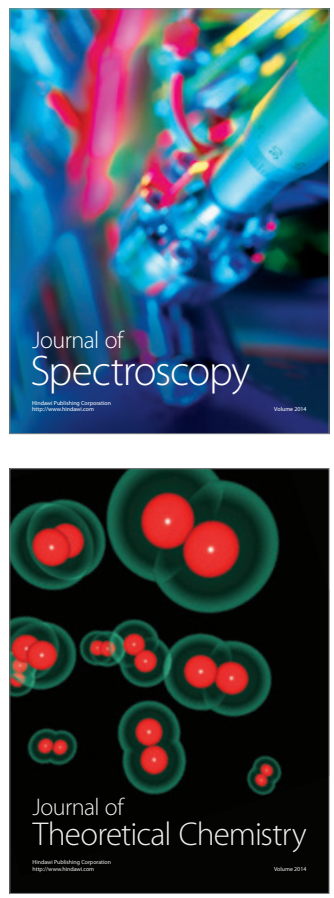
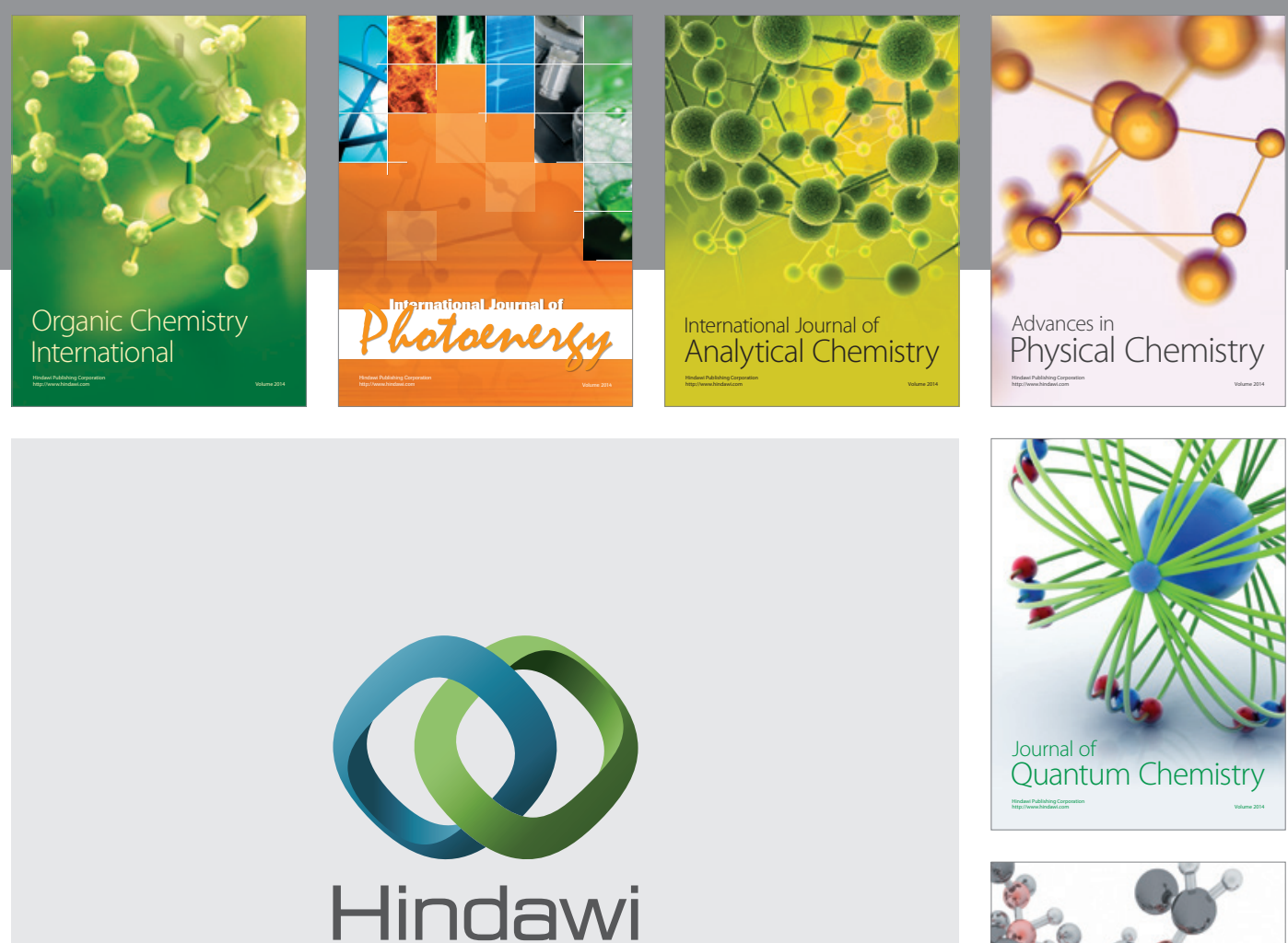

Submit your manuscripts at

http://www.hindawi.com

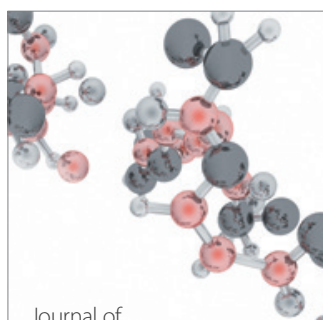

Analytical Methods

in Chemistry

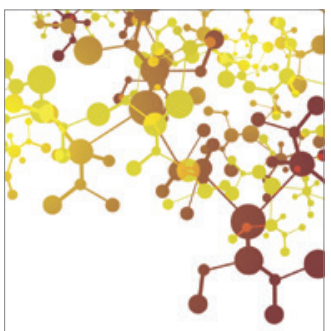

Journal of

Applied Chemistry

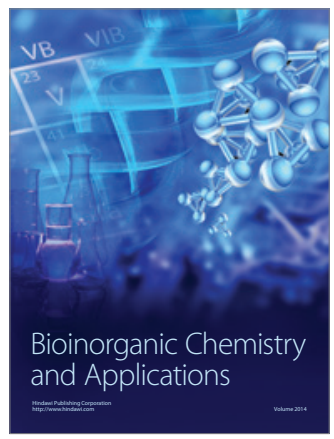

Inorganic Chemistry
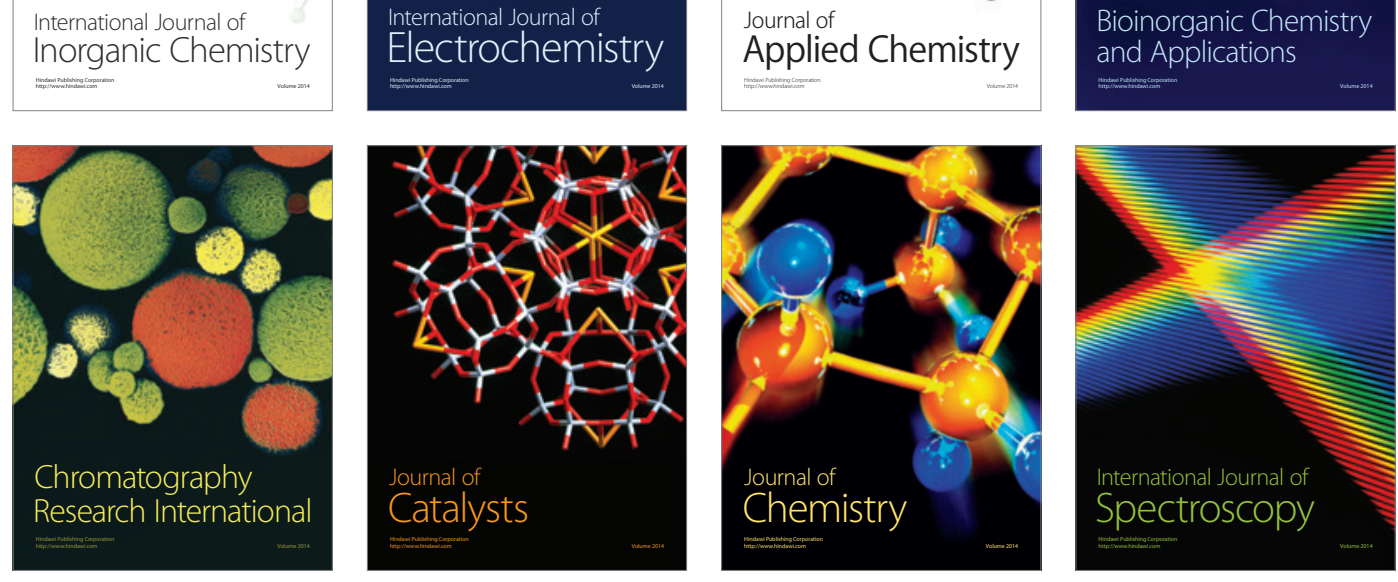